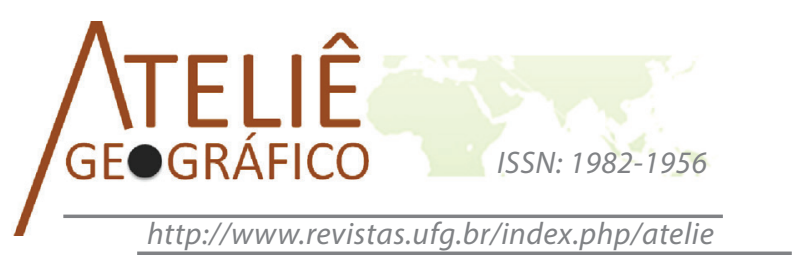

\title{
O Desenvolvimento Humano em ambientes metropolitanos: subsídios teóricos e metodológicos para a mensuração estatística
}

\author{
Human Development in metropolitan environments: \\ theoretical and methodological subsidies for the statistical \\ mensuration
}

El Desarrollo Humano en medios metropolitanos: aportes
teóricos y metodológicos para la mensuración estadística

\author{
Diego Pinheiro Alencar \\ Instituto Federal Goiano - Campus Posse \\ diegopinheiroalencar@yahoo.com.br \\ Juheina Lacerda Ribeiro Viana \\ Instituto Federal Goiano - Campus Iporá \\ juheinalacerda@hotmail.com
}

\begin{abstract}
Resumo
O levantamento de varáveis vinculado ao desenvolvimento humano se apresenta sempre enquanto exercício complexo, fato que é otimizado quando se trata de ambientes metropolitanos. Esserecorte espacial é caracterizado dentre outros fatores, por intensas contradições socioeconomicas, materializadas em diferentes contextos, como habitação, acesso à bens e consumo e oportunidades de mobilidade. Os deslocamentos intrametropolitanos são apresentados enquantopossibilidade de integração das demandas metropolitanas, fato que o torna a mobilidade, elemento central na discussão da qualidade de vida nos ambientes metropolitanos. Nesse sentido, a produção/organização dos indicadores relacionados ao desenvolvimento humano em Regiões Metropolitanas, se caracteriza como proposta negligente quando desconsidera os elementos relacionados aos deslocamentos populacionais cotidianos.
\end{abstract}

Palavras-Chave: Desenvolvimento Humano; Regiões Metropolitanas; Indicadores Estatísticos. 


\begin{abstract}
The gathering of variables linked to human development is always presented as a complex exercise, fact optimized when the subject is metropolitan environments. This spatial scope is characterized, among other factors, for intense social and economic contradictions, materialized in different contexts as housing, access to goods and oportunities of mobility. The intrametropolitan displacements are presented as possibility of integration of metropolitan demands, fact that turns mobility a central element in the discussion of life quality in metropolitan environments. Thus, the production/organization of indexes related to human development in Metropolitan Regions characterize itself as a negligent proposal when elements related to daily population displacements are not considered.
\end{abstract}

Keywords: Human Development. Metropolitan Regions. Statistical Indexes.

\begin{abstract}
Resumen
La encuesta de variables relacionadas con el desarrollo humano se presenta siempre como un ejercicio complejo, un hecho que se optimiza cuando se trata de entornos metropolitanos. Esta área espacial se caracteriza, entre otros factores, por las contradicciones socioeconómicas intensas incorporadas en diferentes contextos, como la vivienda, el acceso a los bienes y las oportunidades de consumo y movilidad. Los desplazamientos intra-metropolitanos san presentados mientras posibilidad para integración de las demandas metropolitanas, un hecho que hace la movilidad un elemento central en la discusión a respecto de la calidad de vida en entornos metropolitanos. En este sentido, la producción / organización de los indicadores relacionados con el desarrollo humano en las áreas metropolitanas se caracteriza por ser una propuesta negligente cuando no tiene en cuenta los elementos relacionados con el desplazamiento diario de la población.
\end{abstract}

Palabras clave: Desarrollo Humano; Las áreas metropolitanas; Los indicadores estadísticos.

\title{
Introdução
}

O presente texto consiste em um ensaio teórico e metodológico referente à mensuração do desenvolvimento humano, verticalizando o estudo na análise e problematização do Atlas de Desenvolvimento Humano das Regiões Metropolitanas Brasileiras. A metodologia adotada para direcionar a proposta consiste nos seguintes aspectos: 1. Revisão bibliográfica referente às temáticas de desenvolvimento humano, metropolização e mobilidade urbana-metropolitana; 2. Análise de indicadores secundários relacionados ao desenvolvimento humano nas Regiões Metropolitanas (RMs), bem como, dos dados disponibilizados pelo Censo Demográfico de 2010;

A discussão que se segue, considera as metrópoles, como espacialidades repletas de contradições socioespaciais, dentre essas, destacando a mobilidade intrametropolitana. As condições de locomoção cotidiana expressam contradições socioespaciais sintomáticas da crise metropolitana brasileira, a exemplo dos congestionamentos, precarização do transporte coletivo, crescimento de acidentes de trânsito, dentre outros. Posto isto, defende-se a ideia que o desenvolvimento de variáveis estatísticas para 
mensurar a qualidade de vida nesses ambientes, faz-se incompleto quando negligenciase as condições de locomoção.

No Brasil, a mensuração do desenvolvimento humano foi realizada em diferentes recortes espaciais (município, unidades federativas, território nacional e regiões metropolitanas). Em comum entre os recortes estão as variáveis selecionadas para mensuração estruturadas nos seguintes eixos: trabalho e renda, aspectos educacionais, características demográficas e infraestrutura domiciliar. Percebe-se que as especificidades espaciais, bem como as disparidades regionais são desconsideradas na análise. Para problematizar essa metodologia, estruturamos a proposta em três momentos: o primeiro, aborda o conceito de desenvolvimento humano e a complexidade existente em sua mensuração estatística. O segundo, discute as dinâmicas socioespaciais das RMs brasileiras, demonstrando como essa forma de organização espacial interfere diretamente na qualidade de vida da população. Por fim, trata-se de apontamentos teóricos e metodológicos que apontam para os limites e possibilidades da inclusão de variáveis relacionadas à mobilidade na mensuração do IDH.

\section{A mensuração do desenvolvimento humano}

A gente não quer só comida A gente quer comida diversão e arte

(...) A gente não quer só comer A gente quer comer e fazer amor

A gente não quer só comer A gente quer prazer pra aliviar a dor

(Titãs, 1987)

Os versos decantados pela banda de rock Titãs ao final da década 1980 narram a dificuldade de abordar elementos vinculados à subjetividade humana, quando se considera o sentimento de satisfação. Estão presentes nos versos aspectos relacionados à práticas sociais que extrapolam a noção de necessidades biológicas dos indivíduos, considerando também elementos culturais, sociais, econômicos e afetivos.

Arendt (2014) aborda a complexidade de pensar uma definição conceitual para o ser humano, demonstrando o quão intrigante se torna a problemática, em que, a ciência conseguiu definir praticamente todos os fenômenos naturais e sociais, entretanto, foi incapaz de fazer o mesmo sobre a natureza humana. Essa limitação está relacionada às diversas possibilidades de ação dos sujeitos, variando de acordo com o tempo e o espaço. Não se trata de afirmar que o espaço é um determinante das relações socias, mas sim que as influencia, nessa perspectiva, a autora enuncia que:

Tudo que adentra o mundo humano por si próprio, ou para ele é trazido pelo esforço humano, torna-se parte da condição humana. O impacto da realidade do mundo sobre a existência humana é sentido e concebido como força condicionante. A objetividade do mundo - seu caráter-de-objeto ou seu caráter-de-coisa e a condição humana complementam-se uma à outra; por ser uma existência condicionada, a existência humana seria impossível sem coisas, e 
estas seriam um amontoado de artigos desconectados, um não-mundo, se não fossem os condicionantes da existência humana (Arendt, 2014, p. 11).

A relação entre o ser humano e o espaço ocorre de maneira integrada, em que ao mesmo tempo que produz o espaço tem suas práticas condicionadas ao mesmo. Ao longo dos séculos essa organização e adaptação foi se desenvolvendo por meio das necessidades humanas. Evidentemente as demandas humanas contemporâneas ganharam alto teor de complexidade, de forma que apenas os aspectos biológicos são insuficientes. Mas afinal, como compreender as necessidades humanas na sociedade atual? Marcuse (1964) baseando-se na lógica da sociedade industrial, traz para o debate a relação das necessidades históricas humanas. $\mathrm{O}$ autor nos coloca diante de duas espécies de necessidades. Inicialmente apresenta as necessidades verídicas, que vincula-se aos aspectos fisiológicos dos seres humanos. Em outro sentido, as chamadas "falsas necessidades", são aquelas impostas aos indivíduos por determinadas instituições sociais, sendo possível afirmar que:

A intensidade, a satisfação e até o caráter das necessidades humanas, acima do nível biológico, sempre foram precondicionados. O fato de se fazer ou deixar de lado, gozar ou destruir, possuir ou rejeitar algo ser ou não tomada por necessidade depende de poder ou não ser ela vista como desejável e necessária aos interesses de instituições sociais comuns (Marcuse, 1964, p. 26).

A compreensão dos elementos essenciais para a vida humana além de uma perspectiva biológica são caracterizados a partir de uma extrema amplitude, a exemplo das especificidades dos grupos sociais, características de gênero, bem como os contextos espaciais abordados. A questão que está posta consiste em uma preocupação metodológica. Afinal, considerando a relação entre a subjetividade das necessidades humanas e as contradições socioespaciais, como selecionar os elementos essenciais para definir as variáveis essenciais para quantificar o desenvolvimento humano em um país, considerando diferentes dimensões territoriais (União, Unidades Federativas, Regiões Metropolitanas e Municípios)?

O conceito de desenvolvimento humano, por si só demonstra uma extrema amplitude de possibilidades e definições. Por desenvolvimento, partimos da concepção aristotélica, que o entende a partir do "movimento em direção ao melhor" (ABBAGNANO, 2007, p. 241). Está evidente na definição a extrema subjetividade que engloba o conceito. O que é "melhor"? A partir de qual definição? Como efetivar o movimento em sua direção? São algumas perguntas que permeiam as análises desenvolvimentistas. Ainda, torna-se prudente, pensar uma definição de humano, para além da perspectiva biológica predominante, mas sim, a partir de uma conjuntura de elementos sociais, econômicos e culturais.

Evidentemente uma proposta de levantamento de variáveis estatísticas que englobam aspectos sociais em uma nação não contemplará as subjetividades individuais. Nesse sentido, faz-se pertinente considerar um paradigma à direcionar as questões abordadas. Sen (2010, p. 29) abordou a perspectiva de desenvolvimento humano a partir da noção de liberdade, em que, "O desenvolvimento tem de estar relacionado, 
sobretudo com a melhora de vida que levamos e das liberdades que desfrutamos", o autor dá continuidade na reflexão a partir da abordagem integrada das noções de êxitos e privações. É indiscutível pensar esses elementos a partir das singularidades, nesse sentido o autor enfatiza que:

Dada a heterogeneidade dos componentes distintos da liberdade, bem como a necessidade de levar em conta as diversas liberdades das diferentes pessoas, frequentemente haverá argumentos em direções contrárias. A motivação que fundamenta a abordagem do "desenvolvimento como liberdade" não consiste em ordenar todos os estados - ou todos os cenários alternativos - em uma "ordenação completa", e sim em chamar a atenção para aspectos importantes do processo de desenvolvimento, cada qual merecedor de nossa atenção (Sen, 2010, p. 52).

A abordagem do desenvolvimento humano a partir da noção de liberdade fazse necessário considerar a disposição de variáveis que reflitam as condições e rupturas das dinâmicas de dominação social. No Brasil, os indicadores selecionados ocorrem a partir do Censo Demográfico, realizado a cada dez anos. Considera-se no total, 232 variáveis disponibilizadas para aplicação em diferentes escalas de análise (unidades de desenvolvimento humano, municípios, estados e Brasil) (Fundação João Pinheiro, $2014)^{1}$.

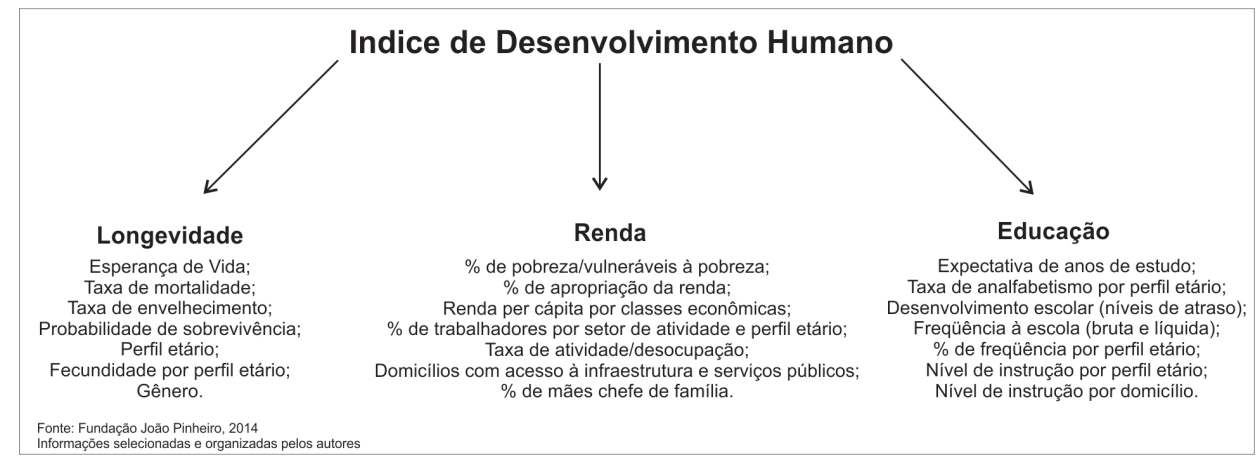

Figura 1. Índice de Desenvolvimento Humano: informações gerais, 2010

Fonte: Fundação João Pinheiro, 2014, organizado pelos autores.

A figura 1 é uma sistematização das variáveis utilizadas na produção do IDH no Brasil. Nota-se que a proposta está estruturada em três eixos temáticos (longevidade, renda e educação). Compreendendo que a idéia de desenvolvimento humano está relacionado à melhora da qualidade de vida dos indivíduos, evidencia-se a negligência para aspectos fundamentais, como por exemplo, as oportunidades de lazer.

1. Ver "Regras e orientações para dar nomes às UDHs e para fazer descrições das UDHs" (Fundação João Pinheiro (2014). 
A análise do índice de desenvolvimento humano é constantemente vinculada à expectativas redução das desigualdades sociais, como por exemplo o índice de gini². Essa condição está estritamente relacionada às perspectivas de justiça e igualdade. Apresenta-se então mais um conceito de ampla complexidade. Justiça! Afinal, o que é justo? Ou então, como apropriar do conceito em cidades, ambientes caracterizados pela heterogeneidade socioeconômica? A obra de Harvey (1980) intitulada "A Justiça Social e a Cidade”, nos direciona a pensar elementos básicos para a reprodução da vida humana nas cidades, englobando aspectos econômicos, sociais e culturais. Nessa perspectiva, podemos afirmar que o levantamento de variáveis que buscam mensurar o desenvolvimento humano nas cidades não deve se basear apenas na centralidade exercida pelo trabalho e seus respectivos resultados, mas também considerar as práticas cotidianas dos sujeitos quantificados, uma vez que essas informações são salutares para a governança urbana.

Não se questiona a relevância dos indicadores de desenvolvimento humano, mas sim, os expõe à ressalvas e problematizações. Nesse sentido, busca-se adiante apresentar elementos essenciais para entender o desenvolvimento humano em regiões metropolitanas, considerando predominantemente as especificidades socioespaciais desses ambientes.

As condições de mobilidade é relatada pela bibliografia como um dos principais impasses de gestão nas Regiões Metropolitanas (RMs). Predominantemente, o transporte coletivo assume protagonismo nessa problemática, uma vez que, ele torna empírico diversas contradições do espaço público. A centralidade exercida pela mobilidade no debate metropolitano está denotado desde a instituição normativa desses ambientes. Tomando como exemplo a Região Metropolitana de Goiânia, em que os serviços relacionados à mobilidade populacional recebe atenção especial (GOIÁS, 1999).

A proposta segue na defesa da ideia da ineficiência de discutir o desenvolvimento humano em espacialidades distintas, a partir das mesmas variáveis. No caso específico de RMs, considera-se negligente abordar essa proposta desconsiderando aspectos vinculados a mobilidade populacional. Os motivos da afirmativa, estão contemplados no tópico seguinte.

\section{Discutindo o recorte espacial}

Os ambientes metropolitanos no Brasil são caracterizados enquanto espacialidades com intensos conflitos sociais, conforme visto em Santos (2009), ao abordar a temática enfatizando que nas metrópoles dos países subdesenvolvidos, em que,se evidencia diversas contradições socioespaciais, como emprego, renda, mobilidade,

2. É um instrumento para medir o grau de concentração de renda em determinado grupo.Ele aponta a diferença entre os rendimentos dos mais pobres e dos mais ricos. Numericamente, varia de zero a um (alguns apresentam de zero a cem). O valor zero representa a situação de igualdade, ou seja, todos têm a mesma renda. O valor um (ou cem) está no extremo oposto, isto é, uma só pessoa detém toda a riqueza. Na prática, o Índice de Gini costuma comparar os $20 \%$ mais pobres com os $20 \%$ mais ricos. No Relatório de Desenvolvimento Humano 2004, elaborado pelo Pnud, o Brasil aparece com Índice de 0,591, quase no final da lista de 127 países. Apenas sete nações apresentam maior concentração de renda (IPEA, 2004). 
acesso a serviços, dentre outros.Essas características trazem especificidades às RMs na abordagem de indicadores estatísticos vinculados ao desenvolvimento humano.

A análise de RMs está pautada em um processo histórico, uma vez que denota a expansão das atividades socioeconômicas da metrópole me direção a outras municipalidades. Essa dinâmica pode ser analisada em alguns exemplos, como a expansão da malha urbana do núcleo metropolitano em direção aos municípios limítrofes, polarização de recursos financeiros, centralização de equipamentos de consumo coletivos, dentre outros. Gouvêa (2005) analisa a metropolização espacial enfatizando que:

$\mathrm{O}$ crescimento das metrópoles brasileiras resultou, fundamentalmente, de um processo de expansão do núcleo central e de absorção gradativa dos espaços periféricos. As relações núcleo-periféricas se intensificaram e se orientaram durante certo tempo, segundo uma estrutura composta de anéis sucessivos, apresentando ciclos de crescimento, de deterioração e de mudanças nos padrões de uso do solo (Gouvêa, 2005, p. 91).

A relação centro-periferia é elementar para compreender a integração metropolitana. O impacto da polarização econômica e de serviços assume centralidade no debate, um vez que na medida em que se centraliza as infraestruturas no núcleo metropolitano, a tendência é que impulsione os deslocamentos intrametropolitanos. Essa dinâmica pode ser abordada, a partir da perspectiva de fixos e fluxos apresentada por Santos (2012). Pensar a mobilidade, caracterizada pelos fluxos é inviável sem a relação o poder de atração dos equipamentos de consumo coletivo centralizados no núcleo metropolitano.

A relação entre metropolização e desenvolvimento humano, deve considerar as especificidades presentes nos diferentes contextos espaciais. Em ambientes metropolitanos um dos elementos essenciais para pensar a qualidade de vida está relacionado às oportunidades de mobilidade. Observando o intenso crescimento das frotas de veículos nas metrópoles brasileiras na última década (DENATRAN, 2012), associado à precarização do transporte coletivo, o trânsito se torna um dos principais impasses de gestão metropolitana. Nota-se também, o impacto direto na vida cotidiana dos indivíduos, a partir do fenômeno denominado por Lefebvre (1991) de "fragmentação do tempo cotidiano". Entender esse processo, a partir da dimensão espacial nos direciona a analisar como as formas espaciais influenciam os processos sociais, assim como exposto por Harvey (1980).

A centralização de estabelecimentos empresariais ativos induz diretamente os deslocamentos para trabalho. Observa-se na figura 2, a centralização das empresas ativas nos núcleos metropolitanos. Destacam-se os casos de Belém, São Luiz e Maceió, que concentraram, respectivamente, $88,74 \%, 86,83 \%$ e $86,67 \%$ das empresas ativas de suas respectivas RMs (IBGE, 2010). Por outro lado, nenhum dos núcleos metropolitanos selecionados apresentaram índices de deslocamentos intrametropolitanos superiores aos demais municípios, fato que nos comprova o impacto que a centralidade na mobilidade dos indivíduos. 


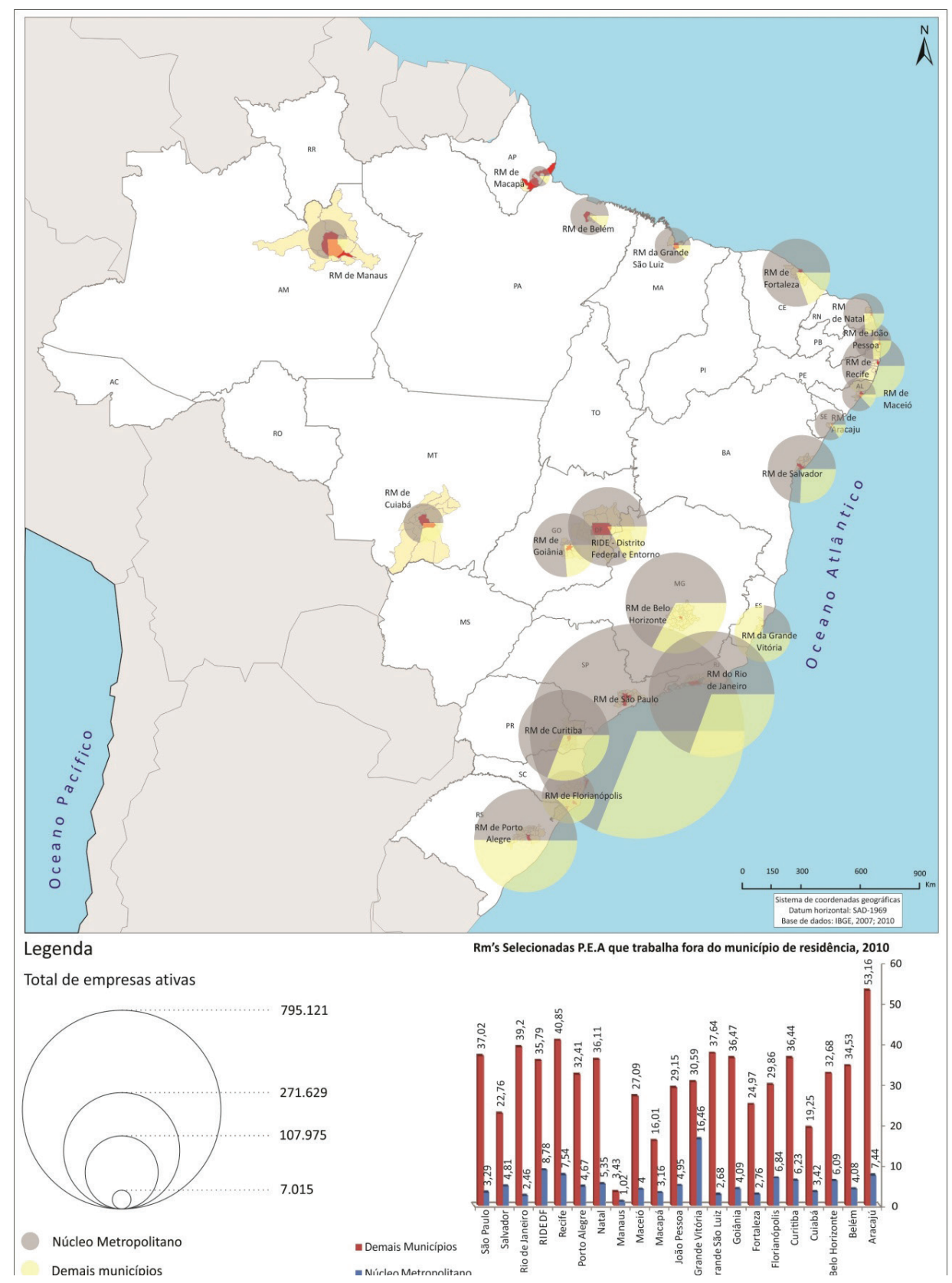

Figura 2. Regiões Metropolitanas selecionadas: deslocamentos intrametropolitanos para trabalho, 2010.

Fonte: IBGE: Censo Demográfico de 2010 e Cadastro Nacional das Empresas, 2010. 
Os modais de locomoção intrametropolitanos no Brasil são predominantemente rodoviários, a partir de veículos automotores e transporte coletivo, por meio das rodovias (federais e estaduais). Observando que nas RMs se concentram os maiores quantitativos de objetos técnicos vinculados à mobilidade, pressupõe-se que nessas regiões ocorra a otimização dos tempos de deslocamentos, como resultado do investimento técnico. Entretanto, essa pressuposição está equivocada. Em decorrência da densificação dos fluxos nesses ambientes, a fluidez e velocidade se encontram comprometidos, fenômeno denominado por Alves (2011) de (i)mobilidade urbana.

Esse processo assume diferentes contornos, a exemplo de longos tempos de deslocamento, motivados pelos congestionamentos ou espera por itinerários do transporte coletivo, aumento de acidentes de trânsito, ou mesmo impactos subjetivos, como o stress causado pela poluição sonora. Lefebvre (1991) se apropriou do termo "psicose do motorista" para definir o impacto dos impasses vinculados à mobilidade na sociedade, sendo assim:

O circular substitui o Habitar, e isso na pretensa racionalidade técnica. É verdade que para muitas pessoas, o carro é um pedaço de sua "moradia", até mesmo o fragmento essencial. Talvez fosse bom insistir em alguns fatos curiosos. No trânsito automobilístico, as pessoas e as coisas se acumulam. É um caso surpreendente da simultaneidade sem troca, ficando cada elemento na sua caixa, cada um bem fechado na sua caraçapa. Isso contribui também para deteriorar a vida urbana e para criar a "psicologia", ou melhor a psicose do motorista (Lefebvre, 1991, p. 110 e 111).

$\mathrm{Na}$ mesma linha argumentativa, Harvey (1980) expõe a subjetividade dos impactos da mobilidade espacial nos indivíduos, em que vincula a mobilidade ao acesso de bens e serviços. Para o autor:

Acessibilidade a oportunidades de emprego, recursos e serviços de bem estar pode ser obtida somente por um preço, e esse preço é, geralmente, igualado ao custo de superar distâncias, de usar o tempo etc. Mas, não é fácil medir o preço que as pessoas pagam. Considere-se, por exemplo, a dificuldade de dar algum valor ao tempo de estudos de transporte. E há mesmo outros problemas mais complicados envolvidos aqui, porque o preço social que as pessoas são forçadas a pagar, para ter acesso a certas facilidades é algo que pode variar desde o simples custo direto envolvido no transporte até o preço emocional e psicológico imposto a um indivíduo que tem resistência intensa a fazer alguma coisa (a espécie do preço que pode ser extorquido, por exemplo, de alguém que tem que sujeitar-se a um teste de espera para qualificar-se para o bem estar). (Harvey, 1980, p. 45).

A definição de impactos da precarização da mobilidade nos seres humanos é um elemento de difícil mensuração. Entretanto, reenfatizamos que pensar em propostas de mensuração da qualidade de vida humana em ambientes metropolitanos sem considerar os elementos que induzem e possibilitam a mobilidade espacial é uma análise negligente. 


\section{Mobilidade e desenvolvimento humano}

Analisar o desenvolvimento humano em um determinado recorte espacial se caracteriza como atividade de alta complexidade. Vejamos alguns exemplos. Primeiro, partimos do aspecto de rendimento domiciliar per capita. Será que podemos enquadrar na mesma classificação, grupos sociais com rendimento " $\mathrm{X}$ " residentes em Brasília, Marabá e Goiânia? Evidente que as características socioespaciais de uma região, estado ou município interfere incisivamente no que se pode fazer ou adquirir com um rendimento " $\mathrm{X}$ ".

A possibilidade de se locomover em ambientes metropolitanos se caracteriza enquanto elemento que vai em direção oposta à noção de "desenvolvimento como liberdade" como apresentado por Sen (2010). Contrapomos essa perspectiva com o conceito de (i)mobilidade urbana abordado em Alves (2011). A autora, ao analisar a metrópole de São Paulo observou um processo dicotômico, pois, simultaneamente em que se otimiza a circulação de capitais e informações, também se precariza as condições de locomoção populacional. Está exposto nessa dinâmica uma questão de dominação social, assim como nas palavras de Bauman (2001, p. 17) em que "A velocidade desenvolvimento e o acesso a meios mais rápidos de mobilidade chegaram aos tempos modernos à principal ferramenta do poder e da dominação". Nota-se, sobretudo, em RMs que as condições de mobilidade se apresentam enquanto aspectos de privação da liberdade individual.

Alguns aspectos específicos devem ser considerados para o desenvolvimento da proposta.Compreende-se que a mobilidade é um elemento essencial para entender a vida metropolitana. Por exemplo, toma-se os aspectos educacionais como um eixo estruturante do IDH, por outro lado desconsidera-se a distância e tempo habitual de deslocamentos efetivados pelos estudantes. Ribeiro e Koslinski (2010),tendo como recorte espacial, o município do Rio de Janeiro, enfatizaram como as questões locacionais, bem como oportunidades de locomoção influenciam diretamente na frequência e rendimento escolar na educação básica. Concordando com essa análise, enfatiza-se que a compreensão as condições de locomoção populacional influenciam diretamente nas variáveis vinculadas à educação,a exemplo da "expectativa de anos de estudo, níveis de escolarização por faixa etária e \% de crianças fora da escola".

Indicadores sociais analisados em uma perspectiva exógena ao espaço podem estar repletos de contradições. A mobilidade também influencia diretamente atividades voltadas ao trabalho, repercutindo diretamente nos rendimentos. Pensar aspectos como "\% de pobres, renda per capita e \% de empregados sem carteira" nos remetem a pensar como esses indivíduos estão inseridos na "fábula" da integração metropolitana.

O quadro 01, apresenta variáveis que contribuiriam para discutir o desenvolvimento humano em ambientes metropolitanos. 
Quadro 1. Variáveis vinculadas ao desenvolvimento humano em ambientes metropolitanos

\begin{tabular}{|l|l|}
\hline $\begin{array}{l}\text { Tempo habitual de deslocamento } \\
\text { Residência - Trabalho }\end{array}$ & $\begin{array}{l}\text { ( ) } 0 \text { a } 5 \text { min ( ) } 6 \text { a } 30 \text { min ( ) } 31 \text { a } 60 \text { min } \\
\text { ( ) Entre } 1 \text { e } 2 \text { horas ( ) Mais de } 2 \text { horas }\end{array}$ \\
\hline Local de exercício do trabalho principal & $\begin{array}{l}\text { ( ) Município de residência ( ) Outro Município } \\
\text { ( ) País estrangeiro }\end{array}$ \\
\hline Local da escola ou creche que frequentam & $\begin{array}{l}\text { ( ) Município de residência ( ) Outro Município } \\
\text { ( ) País estrangeiro }\end{array}$ \\
\hline
\end{tabular}

Fonte: Elaboração dos autores

Fica evidente a contribuição do Censo Demográfico para a produção do IDH, pois todos os indicadores mencionados já são quantificadas a cada década. As variáveis apresentadas contribuem diretamente para entender o desenvolvimento humano em um ambiente metropolitano. A qualidade de vida está vinculada além de elementos econômicos e materiais às práticas cotidianas, como um simples passeio em família, ou alguns minutos a mais de descanso no horário de almoço. Alguns ideais estiveram presentes no imaginário da população brasileira de modo geral, como por exemplo, o "sonho da casa própria" mesmo que ela seja quitada durante o restante da vida, assim como o acesso ao veículo particular.

A aquisição de um veículo automotor particular se tornou cada vez mais acessível nas metrópoles brasileiras. O "carro" deixa de ser apenas um meio de transporte, mas também é concebido enquanto um "status" social. Maricato (2011, p. 177) expõe que "Ao comprar o automóvel, o consumidor adquire não apenas um meio de se locomover, mas também masculinidade, potência, aventura, poder, segurança, velocidade, charme, entre outros atributos".

Nos ambientes metropolitanos brasileiros, o automóvel se tornou um predicato da qualidade de vida, sobretudo, pela precarização do transporte coletivo. Essa dinâmica, não é exclusividade da experiência metropolitana brasileira. Davis (2006) aponta para a estruturalidade do impasse, em que:

Os moradores das favelas por sua vez, têm aguda consciência do perigo que é o trânsito selvagem que engarrafa as ruas da maioria das cidades do Terceiro Mundo. O crescimento urbano desordenado, sem o correspondente investimento em transportes de massas, ou vias expressas com trevos e viadutos transformou o trânsito em uma catástrofe para a saúde pública. Apesar do pesadelo do engarrafamento, o uso de veículos motorizados nas cidades em desenvolvimento disparou (Davis, 2006, p. 136).

$\mathrm{O}$ autor demonstra a importância dos investimentos nos transportes de massas para a redução dos impasses vinculados à mobilidade. As condições de locomoção nos ambientes metropolitanos do Brasil, perpassam não apenas a esfera política e administrativa, uma vez que, as políticas de mobilidade associam-se diretamente à lógica capitalista de produção do espaço. Nesse sentido, a qualidade de vida da população torna-se elemento de segunda importância. 


\section{Considerações Finais}

O desenvolvimento humano é um processo que pode ser abordado em diferentes perspectivas, como associado a liberdade, condições financeiras, aspectos intelectuais, dentre outros. Em comum entre ambos, consiste o fato, da associação com a qualidade de vida dos indivíduos. Compreendendo que o indivíduo não está dissociado do espaço geográfico, afirma-se que não é possível discutir os IDHs sem considerar os elementos espaciais.

A mensuração e espacialização do IDH no Brasil, nos remete à metodologia utilizada pela corrente epistemológica teorética e quantitativa, muito disseminada entre as décadas de 1950 e 1970. Assim como nesse período, a análise do desenvolvimento humano no Brasil, tomou o espaço como uma planície neutra, sem conflitos ou contradições sociais e econômicas. Quando remetida à análise de ambientes metropolitanos, essa concepção espacial torna-se ainda mais insatisfatória, pois as metrópoles brasileiras, são espacialidades repletas de contradições e conflitos.

Dentre os elementos que são negligenciados para discutir o desenvolvimento humano em Regiões metropolitanas, destacamos os indicadores vinculados aos deslocamentos cotidianos. Defende-se que a mobilidade é o principal vetor de integração das demandas metropolitanas, o que a torna aspecto salutar essencial a ser considerado nessa espécie de análise.

Enfim, a proposta de análise não remete ao desenvolvimento um modelo de mensuração do IDH, mas sim, em uma contribuição teórico e metodológica para compreender como esses indicadores se espacializam nas RMs brasileiras. Ressalta-se que a inclusão das variáveis relacionadas à mobilidade não demandaria acréscimos de custos ou trabalho, uma vez que todos os indicadores apontados, já são coletados pelo Censo Demográfico.

\section{Referências}

ABBAGNANO, Nicola. Dicionário de filosofia. São Paulo: Martins Fontes, 2007.

AGAMBEN, Giorgio. Estado de exceção. São Paulo: Boitempo, 2004.

ALVES, Glória da Anunciação. A Mobilidade/Imobilidade na produção do espaço metropolitano. In: CARLOS, A.F.A. Souza, M.L. SPOSITO, M.E.B. A Produção do Espaço Urbano: Agentes e Processos, Escalas e Desafios. São Paulo: Contexto, 2010. Pág. 109 - 122 .

ARENDT, Hannah. A condição humana. 11ed. Rio de Janeiro: Forense Universitária, 2014.

CARLOS, A. F. A. A condição espacial. São Paulo: Contexto, 2011.

DEPARTAMENTO NACIONAL DE TRÂNSITO - DENATRAN. Anuários Estatísticos: Frota de Veículos 2002 - 2012. Brasília, 2012. Disponível em: http://www. denatran.gov.br/frota.htm. 
GOUVÊA, Ronaldo Guimarães. A Questão Metropolitana no Brasil. Rio de Janeiro: Editora FGV, 2005, p. 324;

FUNDAÇÃO JOÃO PINHEIRO. Regras e orientações para dar nomes às UDHs e para fazer descrições das UDHs. Belo Horizonte: Fundação João Pinheiro, 2014.

INSTITUTO BRASILEIRO DE GEOGRAFIA E ESTATÍSTICA. Censo Demográfico de 2010. Rio de Janeiro: IBGE, 2010;

INSTITUTO DE PESQUISA ECONÔMICA APLICADA - IPEA. Desafios do desenvolvimento. Brasília, 2004.

HARVEY, David. A justiça social e a cidade. São Paulo: Hucitec, 1980.

LEFEBRVE, Henri. A vida cotidiana no mundo moderno. São Paulo: Editora Ática, 1991.

MARCUSE, Hebert. A ideologia da sociedade industrial. Rio de Janeiro: Zahar Editores, 1964.

MARICATO, Erminia. O Impasse da Política Urbana no Brasil. Rio de Janeiro: Editora Vozes, 2011.

PROGRAMA DAS NAÇÕES UNIDAS PARA O DESENVOLVIMENTO HUMANO - PNUD. Atlas do Desenvolvimento Humano nas Regiões Metropolitanas Brasileiras. Brasília, 2014.

SANTOS, Milton. Por uma economia política da cidade. São Paulo: Edusp, 2009. 2012. . A Natureza do Espaço: técnica e tempo, razão e emoção. São Paulo: EDUSP,

SEN. Amartya. A ideia de justiça. São Paulo: Companhia das Letras, 2011.

RIBEIRO, Luiz César de Queiroz Koslinski. Mariane. C. A Metropolização da Questão Social e as Desigualdades de Oportunidades Educacionais no Brasil. In: RIBEIRO, L.C.Q. Koslinski, M.C. Alves, F. Lasmar, C. Desigualdades Urbanas Desigualdades Escolares. Rio de janeiro: letra Capital, 2010. Pág. 334.

TITÃS. Jesus não tem dentes no país dos banguelas. Rio de Janeiro: Estúdio nas Nuvens, 1987.

\section{Diego Pinheiro Alencar}

Doutorando em Geografia pela Universidade Federal de Goiás, Mestre e graduado em geografia pela mesma instituição. Atualmente é professor efetivo do Instituto Federal Goiano, Campus Iporá.

Rua Dias, Qd. 4A, Bairro Mato Grosso, Iporá, Goiás.

diegopinheiroalencar@yahoo.com.br 
JuHEINA LACERDA RibEIRO Viana

Possui mestrado pela Universidade Federal de Goiás e graduação pela mesma instituição. Atualmente é professora do Instituto Federal Goiano, Campus Iporá. Rua Dias, Qd. 4A, Bairro Mato Grosso, Iporá, Goiás.

juheinalacerda@hotmail.com

Recebido para publicação em agosto de 2016 Aprovado para publicação em novembro de 2016 